Genij Ortopedii. 2021. Vol. 27, no. 5. P. 555-561.

Original article

https://doi.org/10.18019/1028-4427-2021-27-5-555-561

\title{
Risk factors for lethal outcomes after surgical treatment of patients with chronic periprosthetic hip joint infection
}

\section{V.A. Artyukh ${ }^{\bowtie}$, S.A. Bozhkova, R.M. Tikhilov, A.V. Yarmilko, Yu.V. Muravyova}

Vreden National Medical Research Center of Traumatology and Orthopedics, Saint Petersburg, Russian Federation Corresponding author: IVasilii A. Artyukh artyukhva@mail.ru

\begin{abstract}
Introduction Periprosthetic joint infections (PJI) are serious complications of total hip arthroplasty (THA) and affect the patient's life expectancy. The aim of the study was to identify independent factors influencing the risk of death in patients with PJI after revision THA. Materials and methods The study included 51 lethal outcomes in patients with chronic PJI of the hip. Results and discussion In our cohort of 434 patients, 13 (2.99\%) patients died within the first year after surgery ( $p>0.05)$, which is 2.2 times less than similar published data. The result of gender analysis showed no statistically significant differences in the risk of death between men and women (OR1.05 CI $0.59-1.89, \mathrm{p}=0.87$ ). It was found that in patients over 70 years old, the risk of death was significantly higher (OR 2.05 CI 1.09-3.87, $\mathrm{p}=0.031$ ). Additional independent risk factors of death are diseases of the cardiovascular system. It was not possible to find a statistically significant effect of the nature of infection on the risk of death: no growth (OR 2.23, CI 0.52-9.61), monomicrobial infection (OR 1.98, CI $0.45-8,73$ ), polymicrobial infection (OR 3.2, CI 0.71-14.45, p > 0.05). Conclusion The mortality rate during the first year after revision THA in patients with PJI was $2.99 \%$, which is lower than the results of other researchers. In the next 2-3 years, the rate of death increases 3.9 times. The main independent risk factors are the age of patients and concomitant diseases of the cardiovascular system.
\end{abstract}

Keywords: periprosthetic joint infection, arthroplasty, hip joint, death, exitus letalis

For citation: Artyukh V.A., Bozhkova S.A., R.M. Tikhilov, Yarmilko A.V., Muravyova Yu.V. Risk factors for lethal outcomes after surgical treatment of patients with chronic periprosthetic hip joint infection. Genij Ortopedii, 2021, vol. 27, no 5, pp. 555-561. https://doi.org/10.18019/1028-4427-2021-27-5-555-561

\section{INTRODUCTION}

Modern total hip arthroplasty (THA) is an effective tool in the fight against pain, dysfunction of the lower extremities and has deserved being called an intervention of the century [1]. In hospitals, united by the local register of the Vreden Center, a total of 15,710 THA operations were performed from 2014 to 2018, including 2,611 (16.6\%) revision TA. Interventions for periprosthetic infection (PJI) made $44.8 \%$ [2].

Despite a relatively small number of PJI cases, infectious complications are a serious problem due to the severity of the multifactorial pathological process and high financial costs [3-5]. In most cases, the treatment of PJI requires the use of aggressive surgical techniques, repeated surgeries, long-term systemic antibiotic therapy (ABT), which together affect the patient's life expectancy [6-9].

P. Gundtoft et al. (2017) showed that among the patients who underwent treatment for THA PJI, $8 \%$ died within one year after surgery, while among patients who did not need revision for PJI, mortality was only $3 \%$ [10]. According to B. Zmistowski et al. (2013), mortality was significantly higher $(p<0.001)$ among patients with PJI compared with patients after aseptic revision: $3.7 \%$ and $0.8 \% 90$ days after surgery, respectively, $10.6 \%$ and $2,0 \%$ after one year, $13.6 \%$ and $3.9 \%$ after two years, and $25.9 \%$ and $12.9 \%$ after five years [11]. The authors compared the data obtained with the survival rate after treatment of the five most common cancers: prostate $-99 \%$, breast $89 \%$, lung $-16 \%$, colorectal cancer $-64 \%$ and melanoma - $91 \%[12,13]$.

The study of risk factors leading to death after revision arthroplasty (RA) due to PJI is considered critical for the allocation of health care resources in the next decade [14].

The aim of the study was to identify independent factors influencing the risk of death in PJI patients after THA RA.

\section{MATERIAL AND METHODS}

It was a single-center retrospective study. According to the data of the local register of infectious complications of THA at the department of purulent surgery from 2012 to 2016, 603 patients with PJI were treated, whose data were studied in this work (Fig. 1). Treatment outcomes were assessed during a follow-up examination of patients at the outpatient clinic of the Vreden Center. If the examination in person was impossible, data on the outcome of the disease were collected during by a telephone interviewing of the patient or his close family, as well as from questionnaires received by mail and e-mail.

The inclusion criteria were the following: 1) patients with acute and chronic THA PJI who underwent sanitizing surgery (index intervention); 2) patients who have passed the control examination (survey); 3) patients who died by the time of the study.

The exclusion criterion was patients who are not available for a follow-up examination (survey). 


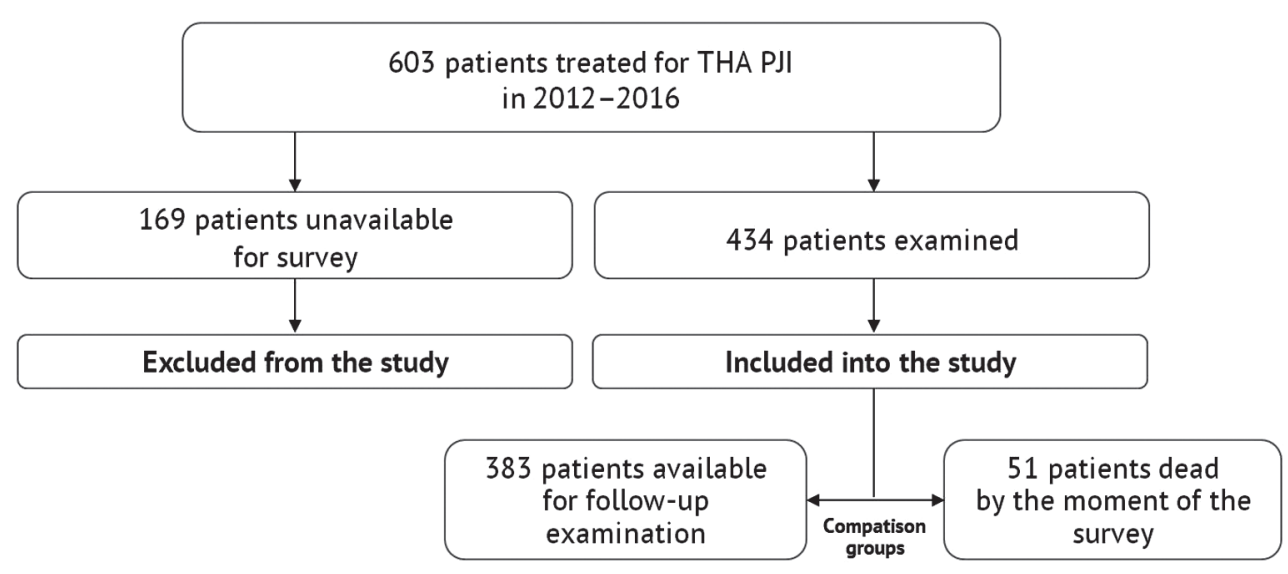

Fig. 1 Diagram of study design

The source of information about inpatient treatment was medical documentation: medical records, operation protocol, and questionnaire data. The study analyzed the sex, age of the patient, medical history (date and indications for primary THA, duration of PJI, number of previous joint surgeries), concomitant diseases, laboratory parameters (hemoglobin, leukocytes, ESR, CRP, fibrinogen), type of index intervention, duration of surgery, blood loss, amount of blood products used.

The diagnosis of PJI was established based on the recommendations of the Musculoskeletal Infection Society (MSIS) (2011), which distinguish two "big" and six "small" signs of infection [15].

In addition, superficial and deep infection of the surgical site was taken into account. Superficial infection was the pathological process limited by the skin and subcutaneous tissue, while deep infectious inflammation involved fascia and peri-implant tissues, including muscles and bone.

The course of PJI was defined as acute or chronic in accordance with the classification of D. Tsukayama et al.. (1996) [16]. The evaluation criterion was the time interval from the last hip arthroplasty to the onset of symptoms of an infectious complication. An acute infection was considered an infection that developed during the first 4 weeks after arthroplasty, or when the first symptoms appeared, if more than a year had passed after the operation.

The choice of the method of surgical intervention was carried out on the basis of the analysis of the depth of the infection process and duration of the disease. In superficial infection, they were limited to excision of the affected tissues with subsequent suturing of the postoperative wound. Revision THA was performed in patients with acute PJI with implant retention. Patients with chronic PJI underwent a two-stage revision arthroplasty, and a one-stage revision in separate cases.

Antibacterial therapy The starting ABT was of a wide range, with the obligatory consideration of the pathogens isolated before the operation. On the eve of the operation or before the beginning of anesthesia, the patient was placed a central venous catheter for parenteral administration of drugs in the perioperative period. If necessary, $\mathrm{ABT}$ was corrected after receiving the results of the intraoperative biological material tests. Monitoring the ABT safety included an assessment of the activity of hepatic transaminases and the level of creatinine.

Ethical standards All manipulations performed in studies on humans were in accordance with the ethical standards of the institutional and / or national research committee as well as the 1964 Declaration of Helsinki and its later amendments or comparable ethical standards. No formal consent was required for this type of study. The minimum follow-up examination period was 2 years after revision arthroplasty for hip PJI.

\section{Statistical analysis}

Registration, systematization of primary data and visualization of the obtained results were performed in Microsoft Office Excel 365 spreadsheets. Statistical analysis was performed using the STATISTICA 10 software. To describe quantitative indicators, a normal distribution test was performed using the KolmogorovSmirnov test. In a normal distribution, to describe the sign, its mean value and standard deviation were used. In distribution other than normal, the median (Me), and the lower $(\mathrm{Q} 1)$ and upper $(\mathrm{Q} 3)$ quartiles $(25-75 \%$ $\mathrm{MCI})$ as scattering measures were used. Comparison of quantitative parameters (age, duration of inpatient treatment, duration of surgery, and volume of blood loss) in the study groups was carried out using the MannWhitney criteria. Categorical data (gender, PJI type, comorbidity, spacer type, and outcome) were described by conditional codes of unmeasured categories that were not subject to ordering. Due to the small number of observations, the comparison of nominal data was carried out using the Pearson chi-square test, corrected for Yates' continuity. Differences between groups were considered statistically significant at $p<0.05$. In order to quantify the dependence of the probability of an outcome on the presence of a risk factor, the odds ratio (OR) was calculated with a $95 \%$ confidence interval (CI). The Kaplan-Meier method of nonparametric statistics was used to assess the survival function based on data on the patient's life years. 


\section{RESULTS}

At the time of the survey, it was possible to find out the condition of $434(100 \%)$ patients, of which 383 $(88.2 \%)$ patients were alive, and 51 (11.8\%) cases were dead. The period of control examination (survey) ranged from 2 to 7 years (Me 47 (30-67.8) months) after the operation. Gender analysis of the group of deceased patients found no significant dependence of deaths on the sex of patients, $47.1 \%(\mathrm{n}=24)$ were women, $52.9 \%$ $(n=27)$ were men $(p=0.86734)$ (Fig. 2).

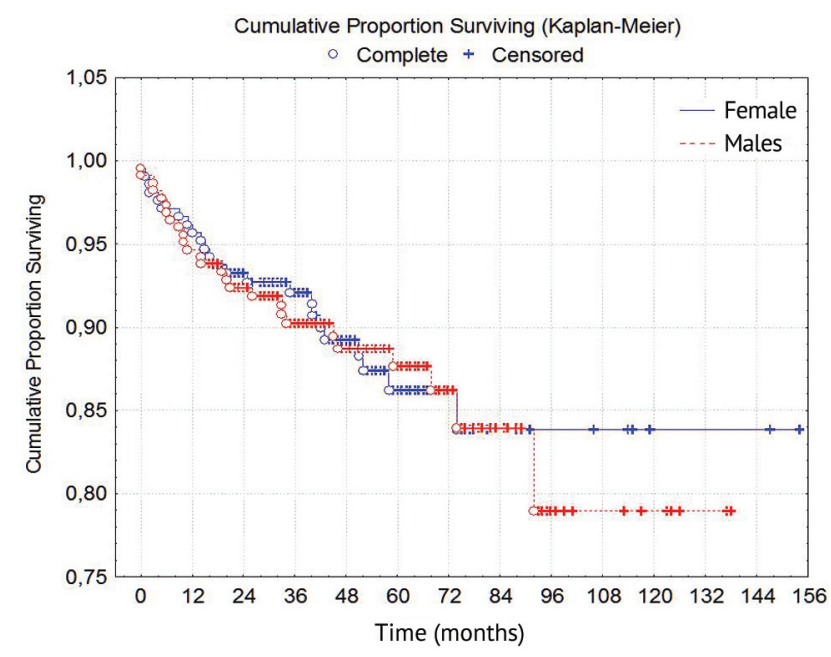

Fig. 2 Survival of patients with PJI after sanitizing surgery and dependence on gender, calculated by the Kaplan-Meier method

The median of the number of operations among the deceased was significantly higher than that in the group of surviving patients and amounted to 2 (1-2) and 1 (1-2), respectively, $\mathrm{p}=0.018$ (Table 1 ).

PJI recurrence by the time of death was registered in $24(47.1 \%)$ patients, of whom more than a half (14 out of
24) underwent from 3 to 10 operations. Among 27 patients who did not have signs of recurrent PJI, the overwhelming majority $(n=23)$ underwent one operation, and only two $(7.4 \%)$ had two surgical interventions each $(p>0.05)$.

The last operation in the group with fatal outcomes was performed for infectious complications in $33(64.7 \%)$ patients, for problems not related to PJI in $18(35.3 \%)$ cases $(\mathrm{p}>0.05)$. In $25.5 \%$ of deceased patients $(n=13)$, the death happened within the first year after surgery for PJI of the hip joint: in $6(11.8 \%)$ cases in the first month after surgery, in 5 (9.8\%) up to 90 days and $2(3.9 \%)$ up to 6 months. In most cases (38 (74.5\%) observations), the lethal outcome occurred more than after a year $(1.7(0.9-2.7)$ years $)$ from the moment of the index intervention. The median age of patients at the time of death was 68 (59.5-76) years. However, the average age of the deceased significantly exceeded the same indicator in the group of survivors: 65 (55-75) years and 58 (49-67) years, respectively $(\mathrm{p}=0.002)$. It was found that in patients over 70 years old, whose portion in the total cohort was $21.2 \%$ $(n=92)$, the risk of death was significantly higher (OR 2.05 CI 1.09-3.87, p = 0.031) (Fig. 3).

Additional independent risk factors for death were concomitant diseases (Table 2). In most cases, those were pathologies of the cardiovascular system.

A comparative analysis of the results of laboratory studies showed that in the group of patients with subsequent lethal outcomes, the levels of inflammation markers (ESR, CRP) upon admission for index surgery were statistically significantly higher than those in the comparison group and a significantly lower hemoglobin level. At the same time, a slower recovery of red blood counts after surgery was noted (Table 3 ).

Table 1

Distribution of types of surgical interventions after performing an index operation

\begin{tabular}{|c|l|c|c|c|}
\hline$\#$ & \multicolumn{1}{|c|}{ Surgical intervention } & PJI recurrence, $\mathrm{n}=24$ & No recurrence, $\mathrm{n}=27$ & $\mathrm{p}$ \\
\hline 1 & Implantation of antibacterial spacer (not removed), $\mathrm{n}(\%)$ & $5(9.8)$ & $17(33.3)$ & $>0.05$ \\
\hline 2 & Total re-implantation, $\mathrm{n}(\%)$ & $6(11.8)$ & $8(15.7)$ & $>0.05$ \\
\hline 3 & Resection arthroplasty with the use of m. vastus lateralis, $\mathrm{n}(\%)$ & $11(21.6)$ & $2(3.9)$ & $>0.05$ \\
\hline 4 & Long suppressive therapy, $\mathrm{n}(\%)$ & $2(3.9)$ & 0 & $>0.05$ \\
\hline
\end{tabular}

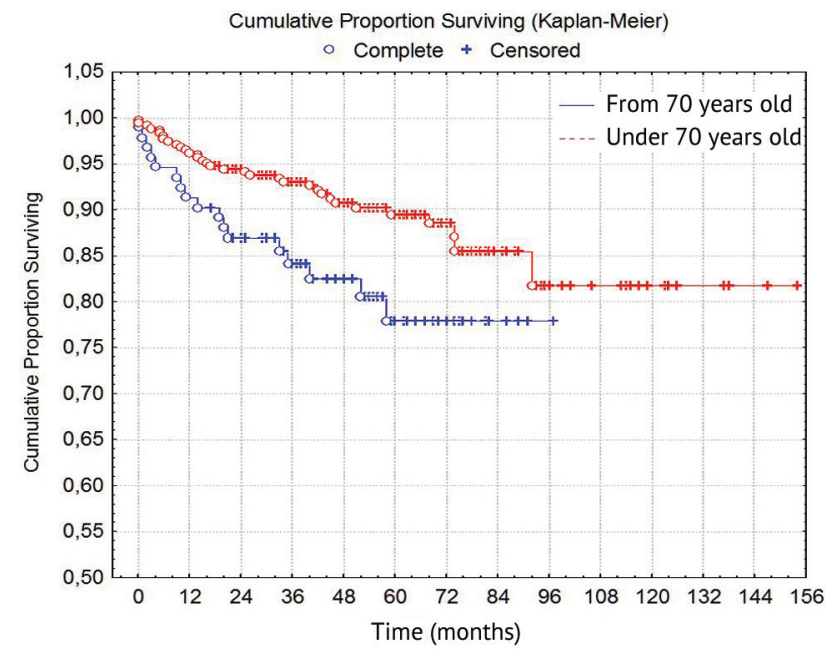

Fig. 3 Survival of patients older than 70 years based on KaplanMeier analysis 
Table 2

Independent risk factors for death during the follow-up period

\begin{tabular}{|c|l|c|r|c|}
\hline$\#$ & \multicolumn{1}{|c|}{ Risk factor } & Odds ratio (OR) & Confidential interval (CI) & $\mathrm{p}$ \\
\hline 1 & IHD & 3.2 & $1.64-6.25$ & 0.00075 \\
\hline 2 & CHF & 2.61 & $1.36-5.01$ & 0.00505 \\
\hline 3 & Heart rate disorders & 2.46 & $1.25-4.81$ & 0.01288 \\
\hline 4 & Arterial hypertension & 2.48 & $1.07-5.75$ & 0.04469 \\
\hline 5 & Diseases of periphery vessels & 2.0 & $1.06-3.77$ & 0.03433 \\
\hline 6 & Respiratory system diseases & 3.12 & $1.59-6.09$ & 0.00117 \\
\hline 7 & Oncologic diseases & 2.68 & $1.13-6.35$ & 0.04288 \\
\hline 8 & Anemia & 3.2 & $1.57-6.54$ & 0.00156 \\
\hline 9 & Intake of anticoaglulants & 4.95 & $2.44-10.03$ & 0.00001 \\
\hline 10 & Diabetes mellitus & 1.57 & $0.68-3.61$ & $>0.05$ \\
\hline 11 & Liver diseases & 1.09 & $0.52-2.32$ & $>0.05$ \\
\hline
\end{tabular}

* IHD - ischemic heart disease; CHF - chronic heart failure

Table 3

Comparative laboratory results

\begin{tabular}{|l|l|c|c|c|}
\hline$\#$ & \multicolumn{1}{|c|}{ Indicator } & Lethal outcomes, $\mathrm{n}=51$ & Patients under follow-up, $\mathrm{n}=383$ & $\mathrm{p}$ \\
\hline \multicolumn{5}{|c|}{ Before intervention } \\
\hline 1 & Hemoglobin & $113(100-121.5)$ & $121(110-133)$ & 0.004 \\
\hline 2 & Erythrocytes & $4.1(3.6-4.5)$ & $4.32(4.0-4.8)$ & 0.536 \\
\hline 3 & ESR & $53(31-84)$ & $44.5(23-66.5)$ & 0.0014 \\
\hline 4 & CRP & $36.9(23.2-60.3)$ & $22.8(9.16-42.8)$ & 0.002 \\
\hline \multicolumn{7}{|c|}{ After intervention (144) day) } \\
\hline 1 & Hemoglobin & $100(93-109)$ & $105(98-112)$ & 0.019 \\
\hline 2 & Erythrocytes & $3.56(3.26-3.78)$ & $3.68(3.39-3.93)$ & 0.048 \\
\hline 3 & ESR & $53(32-69)$ & $42(29-62)$ & 0.28 \\
\hline 4 & CRP & $19.3(11.8-37.3)$ & $16(8.1-30.5)$ & 0.106 \\
\hline
\end{tabular}

Data on the mono- or polymicrobial nature of the infection were available from 396 (91.2\%) patients. In the studied cohort, it was not possible to find a statistically significant effect of the nature of infection on the risk of death: no growth (OR 2.23, CI 0.529.61), monomicrobial infection (OR 1.98, CI 0.458.73), polymicrobial infection (OR 3.2, CI 0.71-14.45, $\mathrm{p}>0.05$ ) (Fig. 4).

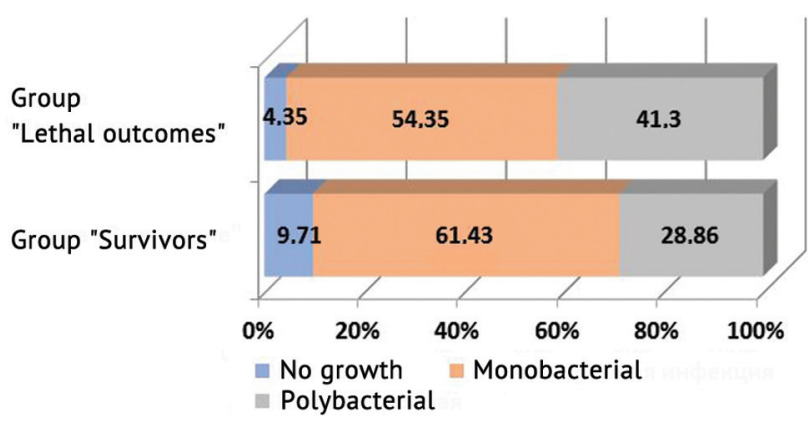

Fig. 4 The nature of the infection (mono- and polybacterial) in the comparison groups

At the same time, the Kaplan-Meier analysis of survival demonstrated greater mortality, predominantly among patients with polymicrobial infection (Fig. 5).

Comparison of intraoperative parameters showed that, despite the similar duration of the operation and the volume of blood loss, the volumes of transfusion of erythrocyte mass and FFP were significantly higher in the group of patients with registered lethal outcomes than in the comparison group (Table 4).

In addition, the analysis of the general indicators of inpatient treatment of patients at the first stage of revision revealed statistically significant differences in the duration of inpatient treatment and its cost (Table 5).

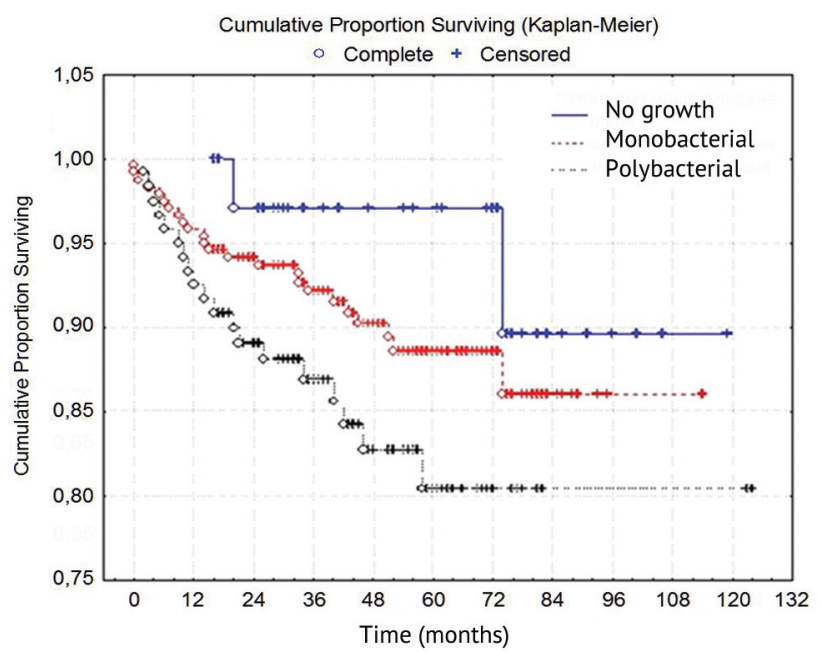

Fig. 5 Survival of patients with different variants of infection based on the analysis according to Kaplan-Meier 
Table 4

Characteristics of the operation, blood products used during the sanitizing stage of revision arthroplasty

\begin{tabular}{|c|l|c|c|c|}
\hline$\#$ & \multicolumn{1}{|c|}{ Parameter } & Lethal outcomes, $\mathrm{n}=51$ & Patients under follow-up, $\mathrm{n}=383$ & $\mathrm{p}$ \\
\hline 1 & Duration of the operation & $175(145-195)$ & $185(150-225)$ & 0.4 \\
\hline 2 & Blood loss & $700(500-1000)$ & $800(500-1100)$ & 0.258 \\
\hline 3 & Transfusion of erythrocyte mass, dose & $2.5(2-4)$ & $2(2-3)$ & 0.000 \\
\hline 4 & Fresh frozen plasma transfusion & $750(600-1410)$ & $600(510-900)$ & 0.000 \\
\hline
\end{tabular}

Characteristics of inpatient treatment at the sanitizing stage of revision TA

Table 5

\begin{tabular}{|c|c|c|c|c|}
\hline$\#$ & Parameter & Lethal outcome, $\mathrm{n}=51$ & $\begin{array}{l}\text { Patients who remained under } \\
\text { follow-up, } n=83\end{array}$ & $\mathrm{p}$ \\
\hline 1 & Bed-days & $28(21-45)$ & $25(21-35)$ & 0.000 \\
\hline 2 & Treatment cost (thousand rubles) & $179(143-255)$ & $148(126-193)$ & 0.000 \\
\hline
\end{tabular}

\section{DISCUSSION}

Mortality is one of the key indicators of the quality of treatment of infectious complications after hip arthroplasty. In the leading industrial countries, this indicator is small and ranges from 1.6-1.9\% in the United States, 2.6-3.3\% in China, 3.1\% in France, and $2.2 \%$ in Spain [17-21]. Unfortunately, data on mortality in the Russian Federation were not available to us.

However, the analysis of works with the objectives similar to ours established that the rate of deaths within a year after the first (sanitizing) operation of a two-stage revision TA is $5.5-10.63 \%$, which is five times higher than the same indicator in aseptic revision [22-25]. J. Cancienne et al. (2017) pointed out that, probably, these indicators do not reflect the real state of affairs, since information about the fate of some patients was absent in national databases [26]. In our cohort of 434 patients, $13(2.99 \%)$ patients died within the first year after surgery ( $p>0.05)$, which is 2.2 times less than the analogous data of J. Cancienne et al. (2017), who identified $6.5 \%$ of deaths within one year after surgery [26].

At the same time, the current death rate can be reduced. Today, researchers note the connection between mortality and socio-demographic factors. Thanks to the allocation of health care resources to underdeveloped regions, during 3-year follow-up C. Zeng et al. recorded a decrease in the number of deaths from $2.9 \%$ in 2013 to $2.6 \%$ in 2016 [27].

Among the socio-demographic risk factors for death, the elderly and senile age of patients are distinguished [28-30]. Statistically significant differences in age were found in patients over 70 years of age and increased by the age of 85-90 years [24, $26,27]$. In our study, the boundary beyond which mortality significantly increased was the age of patients $\geq 70$ years (OR 2.05 CI 1.09-3.87, $\mathrm{p}=0.031$ ).

According to published data, male patients with hip PJI are more at risk of death than women 1-2 years after revision [24, 26, 27]. By comparing treatment results in our studied cohort, no statistically significant differences were found between men and women (OR1.05 CI 0.591.89, $\mathrm{p}=0.87$ ).

Cancienne et al. (2017) analyzed the comorbidity of patients with THA PJI and found that diabetes mellitus, diseases of the heart, lungs, liver and kidneys are among the concomitant diseases [26]. J. Lange et al. (2016) drew attention to the fact that patients who underwent both stages of the two-stage treatment of PJI are younger and have better overall health, in comparison with those patients who underwent only the first stage of revision [22]. In our study, as well as in the work of Bülow E. et al. (2017), there was no statistically significant effect on mortality of factors such as concomitant liver disease [31]. At the same time, the independent risk factors for death were diseases of the cardiovascular and respiratory systems, oncologic diseases, as well as blood diseases (anemia, hypocoagulation by intake of anticoagulants).

The collected information about the treatment outcomes of THA PJI, it was possible to find out that the direct cause of death in $17(33.3 \%)$ cases was the generalization of infectious inflammation, decompensation of cardiovascular disease in $21(41.2 \%)$, complications of oncologic diseases in $4(7.8 \%)$ and renal decompensation in $4(7.8 \%)$. The cause of death in $5(9.8 \%)$ patients remained unknown.

The study had limitations. In accordance with the purpose of the work, independent risk factors for death were established for patients with THA PJI. Howevr, at this stage of the study, similar factors were not disclosed for patients who did not have infectious complications after THA revision. The study did not perform a multivariate analysis of the risks of death. Our work found a trend indicating the impact of pathogenic microflora on lethal outcomes. But, a small number of observations did not allow us to establish the statistical significance of the data. Moreover, due to the lack of information about the patient's condition on the eve of the lethal outcome, we were unable to establish the functional outcomes of treatment. 


\section{CONCLUSION}

The mortality rate during the first year after revision THA that was performed with standard surgical tactics in PJI patients was $2.99 \%$, which is lower than the results of other researchers. In the next 2-3 years, the frequency of deaths increases 3.9 times. The main independent risk

factors are the age of patients and concomitant diseases, primarily diseases of the cardiovascular system. Further study of the identified risk factors will justify the rational choice of staged surgical treatment or suppressive therapy, and propose an individual treatment algorithm.

\section{REFERENCES}

1. Learmonth I.D., Young C., Rorabeck C. The operation of the century: total hip replacement. Lancet, 2007, vol. 370, pp. 1508-1519. DOI: 10.1016/S0140-6736(07)60457-7.

2. Shubniakov I.I., Tikhilov R.M., Denisov A.O., Akhmedilov M.A., Chernyi A.Zh., Totoev Z.A., Dzhavadov A.A., Karpukhin A.S., Muraveva Iu.V. Chto izmenilos v strukture revizionnogo endoprotezirovaniia tazobedrennogo sustava v poslednie gody? [What has changed in the structure of revision hip arthroplasty in recent years?]. Travmatologiia i Ortopediia Rossii, 2019, vol. 25, no. 4, pp. 9-27. (in Russian) DOI: 10.21823/2311-2905-2019-25-4-9-27.

3. Zimmerli W., Trampuz A., Ochsner P.E. Prosthetic-joint infections. N. Engl. J. Med., 2004, vol. 351, no. 16, pp. 1645-1654. DOI: 10.1056/NEJMra040181.

4. Dale H., Børsheim S., Kristensen T.B., Fenstad A.M., Gjertsen J.E., Hallan G., Lie S.A., Furnes O. Perioperative, short-, and long-term mortality related to fixation in primary total hip arthroplasty: a study on 79,557 patients in the Norwegian Arthroplasty Register. Acta Orthop., 2020, vol. 91, no. 2, pp. 152-158. DOI: 10.1080/17453674.2019.1701312.

5. Kurtz S.M., Lau E.C., Son M.S., Chang E.T., Zimmerli W., Parvizi J. Are We Winning or Losing the Battle With Periprosthetic Joint Infection: Trends in Periprosthetic Joint Infection and Mortality Risk for the Medicare Population. J. Arthroplasty, 2018, vol. 33, no. 10, pp. 3238-3245. DOI: 10.1016/j.arth.2018.05.042.

6. Cnudde P., Rolfson O., Timperley A.J., Garland A., Kärrholm J., Garellick G., Nemes S. Do Patients Live Longer After THA and Is the Relative Survival Diagnosis-specific? Clin. Orthop. Relat. Res., 2018, vol. 476, no. 6, pp. 1166-1175. DOI: 10.1007/ s11999.0000000000000097.

7. Ekman E., Palomäki A., Laaksonen I., Peltola M., Häkkinen U., Mäkelä K. Early postoperative mortality similar between cemented and uncemented hip arthroplasty: a register study based on Finnish national data. Acta Orthop., 2019, vol. 90, no. 1, pp. 6-10. DOI: 10.1080/17453674.2018.1558500.

8. Garland A., Gordon M., Garellick G., Kärrholm J., Sköldenberg O., Hailer N.P. Risk of early mortality after cemented compared with cementless total hip arthroplasty: a nationwide matched cohort study. Bone Joint J., 2017, vol. 99-B, no. 1, pp. 37-43. DOI: 10.1302/0301-620X.99B1.BJJ-2016-0304.R1.

9. Huang L., Xu T., Li P., Xu Y., Xia L., Zhao Z. Comparison of mortality and complications between bilateral simultaneous and staged total hip arthroplasty: A systematic review and meta-analysis. Medicine (Baltimore), 2019, vol. 98, no. 39, pp. e16774. DOI: 10.1097/MD.0000000000016774.

10.Gundtoft P.H., Pedersen A.B., Varnum C., Overgaard S. Increased Mortality After Prosthetic Joint Infection in Primary THA. Clin. Orthop. Relat. Res., 2017, vol. 475, no. 11, pp. 2623-2631. DOI: 10.1007/s11999-017-5289-6.

11.Zmistowski B., Karam J.A., Durinka J.B., Casper D.S., Parvizi J. Periprosthetic joint infection increases the risk of one-year mortality. J. Bone Joint Surg. Am., 2013, vol. 95, no. 24, pp. 2177-2184. DOI: 10.2106/JBJS.L.00789.

12.Siegel R.L., Miller K.D., Jemal A. Cancer statistics, 2018. CA Cancer J. Clin., 2018, vol. 68, no. 1, pp. 7-30. DOI: $10.3322 /$ caac.21442.

13.Browne J.A., Cancienne J.M., Novicoff W.M., Werner B.C. Removal of an Infected Hip Arthroplasty is a High-Risk Surgery: Putting Morbidity into Context with Other Major Nonorthopedic Operations. J. Arthroplasty, 2017, vol. 32, no. 9, pp. $2834-2841$. DOI: 10.1016/j.arth.2017.03.061.

14.Goodman S.B. CORR Insights ${ }^{\circledR}$ : How Does Mortality Risk Change Over Time After Hip and Knee Arthroplasty? Clin. Orthop. Relat. Res., 2019, vol. 477, no. 6, pp. 1422-1423. DOI: 10.1097/CORR.0000000000000724.

15.Parvizi J., Zmistowski B., Berbari E.F., Bauer T.W., Springer B.D., Della Valle C.J., Garvin K.L., Mont M.A., Wongworawat M.D., Zalavras C.G. New definition for periprosthetic joint infection: from the Workgroup of the Musculoskeletal Infection Society. Clin. Orthop. Relat. Res., 2011, vol. 469, no. 11, pp. 2992-2994. DOI: 10.1007/s11999-011-2102-9.

16.Tsukayama D.T., Estrada R., Gustilo R.B. Infection after total hip arthroplasty. A study of the treatment of one hundred and six infections. J. Bone Joint Surg. Am., 1996, vol. 78, no. 4, pp. 512-523. DOI: 10.2106/00004623-199604000-00005.

17.Natsuhara K.M., Shelton T.J., Meehan J.P., Lum Z.C. Mortality during Total Hip Periprosthetic Joint Infection. J. Arthroplasty, 2019, vol. 34, no. 7S, pp. S337-S342. DOI: 10.1016/j.arth.2018.12.024.

18.Zuo Y., Lin J., Jin J., Qian W., Qiu G., Weng X. Change in the cause of inpatient mortality after arthroplasty: a retrospective study. J. Orthop. Surg. Res., 2019, vol. 14, no. 1, pp. 180. DOI: 10.1186/s13018-019-1230-x.

19.Kirksey M., Chiu Y.L., Ma Y., Della Valle A.G., Poultsides L., Gerner P., Memtsoudis S.G. Trends in in-hospital major morbidity and mortality after total joint arthroplasty: United States 1998-2008. Anesth. Analg., 2012, vol. 115, no. 2, pp. 321-327. DOI: 10.1213/ ANE.0b013e31825b6824.

20.Le Manach Y., Collins G., Bhandari M., Bessissow A., Boddaert J., Khiami F., Chaudhry H., De Beer J., Riou B., Landais P., Winemaker M., Boudemaghe T., Devereaux P.J. Outcomes after Hip Fracture Surgery Compared with Elective Total Hip Replacement. JAMA, 2015, vol. 314, no. 11, pp. 1159-1166. DOI: 10.1001/jama.2015.10842.

21.Martínez-Huedo M.A., Jiménez-García R., Jiménez-Trujillo I., Hernández-Barrera V., Del Rio Lopez B., López-de-Andrés A. Effect of Type 2 Diabetes on In-Hospital Postoperative Complications and Mortality after Primary Total Hip and Knee Arthroplasty. J. Arthroplasty, 2017, vol. 32, no. 12, pp. 3729-3734. DOI: 10.1016/j.arth.2017.06.038.

22. Lange J., Troelsen A., Søballe K. Chronic Periprosthetic Hip Joint Infection. A Retrospective, Observational Study on the Treatment Strategy and Prognosis in 130 Non-Selected Patients. PLoS One, 2016, vol. 11, no. 9, pp. e0163457. DOI: 10.1371/journal. pone. 0163457.

23.Gomez M.M., Tan T.L., Manrique J., Deirmengian G.K., Parvizi J. The Fate of Spacers in the Treatment of Periprosthetic Joint Infection. J. Bone Joint Surg. Am., 2015, vol. 97, no. 18, pp. 1495-1502. DOI: 10.2106/JBJS.N.00958.

24.Fischbacher A., Borens O. Prosthetic-joint Infections: Mortality over the last 10 years. J. Bone Jt. Infect., 2019, vol. 4, no. 4, pp. 198-202. DOI: 10.7150/jbji.35428. 
25.Inacio M.C.S., Dillon M.T., Miric A., Navarro R.A., Paxton E.W. Mortality after Total Knee and Total Hip Arthroplasty in a Large Integrated Health Care System. Perm. J., 2017, vol. 21, pp. 16-171. DOI: 10.7812/TPP/16-171.

26.Cancienne J.M., Werner B.C., Bolarinwa S.A., Browne J.A. Removal of an Infected Total Hip Arthroplasty: Risk Factors for Repeat Debridement, Long-term Spacer Retention, and Mortality. J. Arthroplasty, 2017, vol. 32, no. 8, pp. 2519-2522. DOI: 10.1016/j. arth.2017.03.018.

27.Zeng C., Lane N.E., Englund M., Xie D., Chen H., Zhang Y., Wang H., Lei G. In-hospital mortality after hip arthroplasty in China: analysis of a large national database. Bone Joint J., 2019, vol. 101-B, no. 10, pp. 1209-1217. DOI: 10.1302/0301-620X.101B10. BJJ-2018-1608.R1.

28.Weiss R.J., Kärrholm J., Rolfson O., Hailer N.P. Increased early mortality and morbidity after total hip arthroplasty in patients with socioeconomic disadvantage: a report from the Swedish Hip Arthroplasty Register. Acta Orthop., 2019, vol. 90, no. 3, pp. $264-269$. DOI: $10.1080 / 17453674.2019 .1598710$.

29.Glassou E.N., Pedersen A.B., Hansen T.B. Is decreasing mortality in total hip and knee arthroplasty patients dependent on patients' comorbidity? Acta Orthop., 2017, vol. 88, no. 3, pp. 288-293. DOI: 10.1080/17453674.2017.1279496.

30.Hailer N.P., Garland A., Rogmark C., Garellick G., Kärrholm J. Early mortality and morbidity after total hip arthroplasty in patients with femoral neck fracture. Acta Orthop., 2016, vol. 87, no. 6, pp. 560-566. DOI: 10.1080/17453674.2016.1234869.

31.Bülow E., Rolfson O., Cnudde P., Rogmark C., Garellick G., Nemes S. Comorbidity does not predict long-term mortality after total hip arthroplasty. Acta Orthop., 2017, vol. 88, no. 5, pp. 472-477. DOI: 10.1080/17453674.2017.1341243.

The article was submitted 17.05.2021; approved after reviewing 02.07.2021; accepted for publication 23.08.2021.

\section{Information about the authors:}

1. Vasilii A. Artyukh - Candidate of Medical Sciences, vaartjuh@win.rniito.ru

2.Svetlana A. Bozhkova - Doctor of Medical Sciences, clinpharm-rniito@yandex.ru

3. Rashid M. Tikhilov - Doctor of Medical Sciences, Professor;

4. Anatoly V. Yarmilko - M.D.;

5. Yulia V. Muravyova - M.D.

Funding and Conflicts of Interest The authors did not receive any funding. There is no conflict of interest. 